\title{
A STUDY ON THE ENERGY CONSUMPTION OF THE ELECTRICAL AND ELECTRONIC HOUSEHOLD AND OFFICE EQUIPMENT IN STANDBY AND OFF- MODE
}

\author{
A. VASILIU, OTILIA NEDELCU, O. MAGDUN, I.C. SĂLIȘTEANU \\ Valahia University of Targoviste, Faculty of Electrical Engineering, Electronics and Information Technology, Aleea \\ Sinaia Street, no 13, postal cod 130004, Targoviste \\ E-mail: vasiliu.andone.ae@valahia.ro, otilia.nedelcu@valahia.ro, oliver.magdun@valahia.ro, \\ cornel.salisteanu@valahia.ro
}

\begin{abstract}
The most recent generation of the electrical and electronic household and office equipment is far more efficient than its predecessor, but it is still improvable. The smart equipment, when it is used, adds the advantages of the supplementary control functions with the requirements of beeing electrically supplied. By interconnecting the smart devices in a data network, some of the energy consumption occurs even in the non-active states. These states, either a "stand-by" mode or an "off-line" mode, according to the European Committee directives, imposes maximum limits for the electricity consumption, thus an eco-design of the electrical and electronic equipment. The impact of these eco-design requirements on household appliances and office equipment with repercussions in their operation and use, as well as the energy and environmental effects, are dealt in this paper, based on a case study.
\end{abstract}

Keywords - low energy consumption, efficiency, eco-design requirements, standby mode

\section{INTRODUCTION}

A general feature of household and office electrical and electronic equipment is that it consumes electricity in onmode and both standby mode or off-mode. These categories of consumption are regulated by Council Regulation (EC), no. 1275/2008 of 17.12.2008 [1], which imposes eco-design requirements for standby consumption, as amended by Regulation (EC) no. $801 / 2013$ [2], on eco-design requirements for household appliances in relation to the standby mode.

According to the EC regulations [1], [2]:

- active "on-mode" of operation is the state in which an equipment is connected to the electrical grid and performs the main functions for which it was designed,

-"stand-by mode" of operation is the state in which an equipment is connected to the electrical grid and provides only the reactivation function with/or without the indication (display) of status information or other information,

-'off-mode' means the condition in which the equipment is connected to the electrical grid and does not perform any function'.

It should be noted that the standby mode is an electricity consumer and in accordance with EC regulations [1] and [2], the power consumed in stand-by mode must be not more than $1 \mathrm{~W}$. For some household and office equipment, stand-by mode is necessary, e.g. the sleep mode operation on laptops and printers, LAN and Wi-Fi network equipment or alarm systems, but for a fairly wide range of devices, the stand-by mode is not necessary, as in this state of operation the equipment does not perform functions for which it was created, i.e.: air conditioning, television, electric ovens, when the consumed electricity is considered a loss of energy.

According to the Monitoring Report on the Implementation of the National Energy Efficiency Action Plan, Section P7 - Energy Efficiency in the Residential Sector [4], it is noted that in Romania, as a result of the alignment with European Union (EU) directives and an increase in living standards, energy consumption in the residential sector has also increased against the background of the continuous increase in the volume of household and office products purchased (predominantly of minimum energy class A and "smart").

Power losses in standby mode at the equipment level of approximately $1 \mathrm{~W}$ seem to be insignificant, but multiplied by the large number of equipment and standby operating time make the energy loss significant and especially unjustified, and as a result of the increasing trend of purchased household appliances, energy losses in the standby mode will also increase.

In this paper, an impact analysis was carried out on a modern residential building with a normal occupancy level, in order to implement the community eco-design requirements on electricity consumption in the off-mode and standby mode of household and office electrical and electronic equipment.

Significant energy losses identified in standby operation mode, amounting to $34 \%$ of the total annual energy consumption of the residential building studied, which require substantial action to be taken with regard to:

- the energy class of equipment to be purchased on the market,

- identifying and implementing measures to reduce standby consumption and,

- changing people's behaviour versus using household and office equipment. 


\section{ACTUAL SITUATION IN THE EUROPEAN UNION}

The rules governing the standby and off-mode consumption in the EU are the EC Regulation, no. 801/2013 on eco-design requirements for household appliances, amending EC Regulation, no. 801/2013 on the design requirements of household appliances, 1275/2008, relative to the standby electrical consumption with information/display state of maximum $1 \mathrm{~W}$ and consumption in off-mode and standby with reactivation of maximum $0.5 \mathrm{~W}$. Particularly, in Romania, according to our knowledge, there are no specific rules to reduce the electricity consumption of household and office equipment in standby and off-mode modes. Only a few informationeducation activities initiated by ANRE (Romanian National Energy Regulatory Authority) were carried out. At European level, measures to increase the energy efficiency have replaced the old household and office equipment with higher energy-class ones. A matter of great importance is that the new generation home appliances are more energy efficient than their predecessors. They are of the smart type or even $5 \mathrm{G}$ generation type and are equipped with additional functions that require to be connected to the electrical grid and interconnected to each other over the LAN or $5 \mathrm{G}$ network, during the period when they are not actively operating.

Currently, according to [3], based on recent measurements carried out in about 1300 households across the EU, the average annual electricity consumption in standby mode was found to be almost $7 \%$ of the total annual energy consumption per household. Further, the International Energy Agency (IEA) estimates a $15 \%$ increase in the standby energy consumption by 2030 [5], [6]. With the objective of measurements of energy loss in standby and off-mode [7], the SELINA project has been launched by ISR - Coimbra University (Portugal). It was geared towards characterising the EU market in terms of standby consumption and off-mode mode of new household and office electrical and electronic equipment, which is sold on the market. The study was carried out on 6318 equipment on a geographically diverse sample of 12 EU Member States between 2009 and 2010, before and after the entry into force of Regulation (EC) 1275/2008 [1] on standby and off-mode energy consumption [7]. Power consumption was recorded in the standby mode and offmodes, in compliance with the requirements of Regulation (EC), no. 1493/1999, 1275/2008 (1W/2W) and EU Regulation, no. $801 / 2013(0.5 \mathrm{~W} / 1 \mathrm{~W})$, showing the percentage of products above the regulatory threshold imposed in 2010 and 2013.

It was found that $18.5 \%$ of the equipment does not meet the EU regulatory threshold of $1 \mathrm{~W}$ for the off-mode electricity consumption. When measurements are compared to the $0.5 \mathrm{~W}$ threshold of 2013 , this percentage increases to $41.5 \%$. In terms of standby consumption, $31 \%$ of the measured products did not meet the EU regulatory limit for the 2010 threshold. When measured values are compared to the 2013 limit, the number of products above the EU regulatory target increases to $66.4 \%$ (Figure 1).

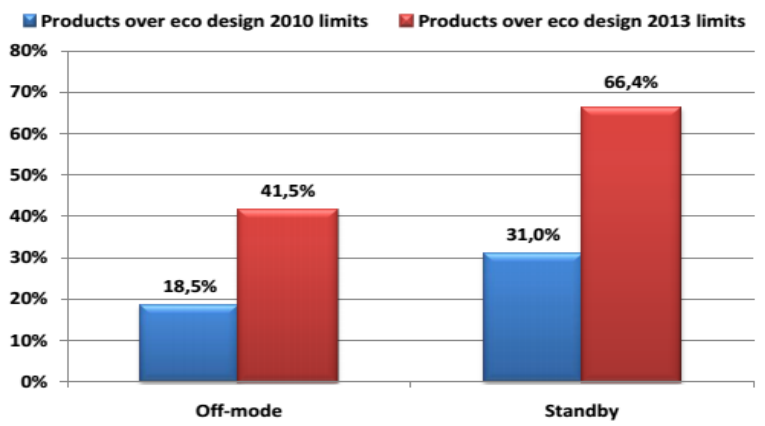

Figure 1. Equipment in the EU with overconsumption [7]

According to [8], for the years 2005 and 2010, the electricity consumption in the EU for standby and offmode modes is of the scale of those presented in Figure 2. For 2010, the study estimated that equipment, worth around EUR 3.7 billion, has been installed in the EU, which has standby/off-mode modes, leading to a standby/off-mode electricity consumption of almost 50 TWh, corresponding to electricity costs of around EUR 7 billion and 20 million tonnes of $\mathrm{CO} 2$ emissions (Figure 1). Combined with other measures to reduce consumption as a result of the purchase of higher energy class equipment (A, A++, etc.) an energy saving of 194 TWh, equivalent to EUR 26.4 trillion and a reduction in $\mathrm{CO} 2$ emissions of 77.6 million tonnes [8] was expected for 2020.

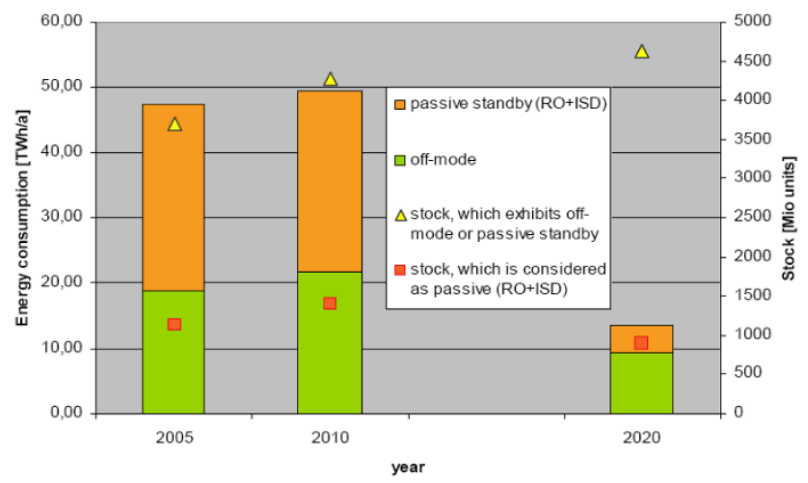

Figure 2. Evolution of the energy consumption in the EU in standby/off-mode and assuming a level of energy consumption 0.5W / 1.0W in 2020 [7], [8]

The commission also named and proposed the consume types 'Hard off-switch' or '0 Watt off-mode' for some equipment. But complying with electromagnetic compatibility and other technical requirements, consumptions of $0.1-0.3 \mathrm{~W}$ cannot be technically avoided and $\mathrm{OW}$ consumptions cannot be technically achievable with the maintenance of minimum electromagnetic compatibility requirements [8]. So the target of "0 Watt" will remain a desiderate.

The design process, manufacturing, purchase of household and office equipment don't keep up with the eco-design requirements imposed by the Regulations (EC), no. $1275 / 2008$ and EU, no. 801/2013. It is estimated that, in 
present (Figure 3) we should consume $10 \%$ of total household energy consumption [6].

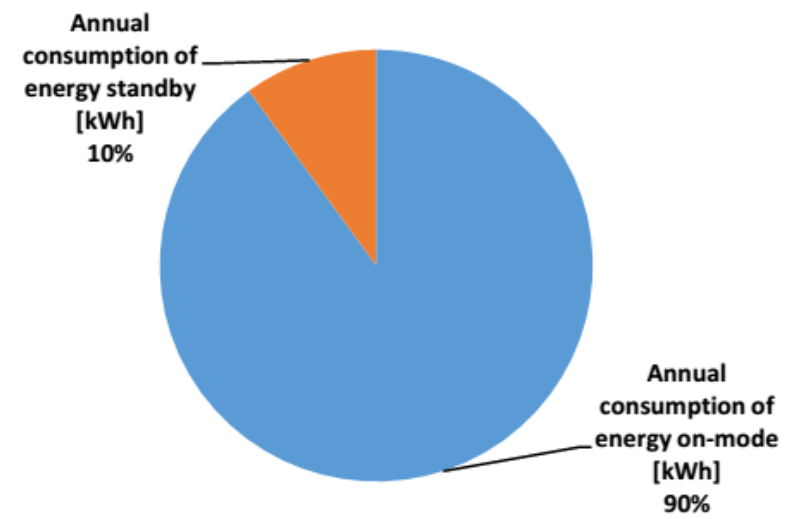

Figure 3. Estimated energy consumption by IEA for 2020 [6]

\section{ENERGY CONSUMPTION OF THE ELECTRICAL AND ELECTRONIC EQUIPMENT IN A RESIDENTIAL BUILDING}

An impact analysis of the implementation of community eco-design requirements on energy consumption in the off-mode and standby mode of the household and office electrical and electronic equipment was carried out. The systematic investigation has been included every consumer, which was connected to the power grid of the residential building, electrical consumers were grouped into two categories:

a) electric lighting lamps: fluorescent low-pressure mercury vapour tubes and low-pressure mercury fluorescent economical lamps, and

b) household and office appliances: air conditioning, gasfired power plant, smart TVs, media box, refrigerators, freezer, washing machine, microwave, electric cooking oven, hood, coffee expressor, dust vacuum cleaner, iron, hairdryer, radio, HI-FI combine, smart phones, laptop, tablet, printer and internet modem. All household and office appliances are energy class $\mathrm{A}$ and $\mathrm{A}+$ and are manufactured between 2012 - 2019 .

By energy consumptions, the energy consumers were highlighted in the active on-mode of operation as well as in the "standby" mode of operation. No household and office consumer analysed shall have a switch intended to be switched off. Switching off mode can be done by physically disconnecting from the grid, where this manoeuvre is available. All consumers destined for electric lighting have only two operating conditions: active on-mode and off-mode (by disconnecting with switches on lighting circuits). So, the power consumption in standby mode is given only by the home appliances and the office consumers.

Following the analysis carried out for consumption, in active and standby operating regimes, and the degree of use of household and office equipment, the most representative situations are:

- high-power appliances, but with a seasonal use of $1.7 \%$, e.g. an air conditioner which standbys a very low current $(8.1 \mathrm{~mA})$ compared to the current consumed in active mode
(2.2A) but, due to the very low use of $1.7 \%$ given the seasonal use, an annual standby consumption (15.14 kWh) is achieved compared to active consumption (70.66 kWh), - smart TVs of low power, with daily use and an unreasonably high standby current (0.11A), almost third part of the current consumed in the active mode (0.29A). Due to the high standby consumption at a daily use of $20 \%$, it results in an annual standby consumption of $175.86 \mathrm{kWh}$ higher than the active operating energy of $92.51 \mathrm{kWh}$.

There is an exaggerated and unjustified annual energy consumption for some categories of household and office equipment, which requires measures for increasing their efficiency. Based on direct performed measurements for each household and office consumer, and corroborated with the occupancy rate of dwelling (two persons as an example), the daily, weekly, monthly and annual operating schedules (on/standby/off) of each consumer household appliances and each lamp, were determined:

- annual energy consumption in the active mode of operation $E_{\text {mod_activ }}$ amounting to $2714.47 \mathrm{kWh}$,

- annual energy consumption in standby $E_{\text {standby }}$ mode of $1385.95 \mathrm{kWh}$,

- total annual energy consumption, amounting to 4100.42 $\mathrm{kWh}$.

The share of consumption by groups of household appliances, from the total household consumption is presented in Figure 4, and the separation of consumption in the two active and standby modes is shown in Figure 5.

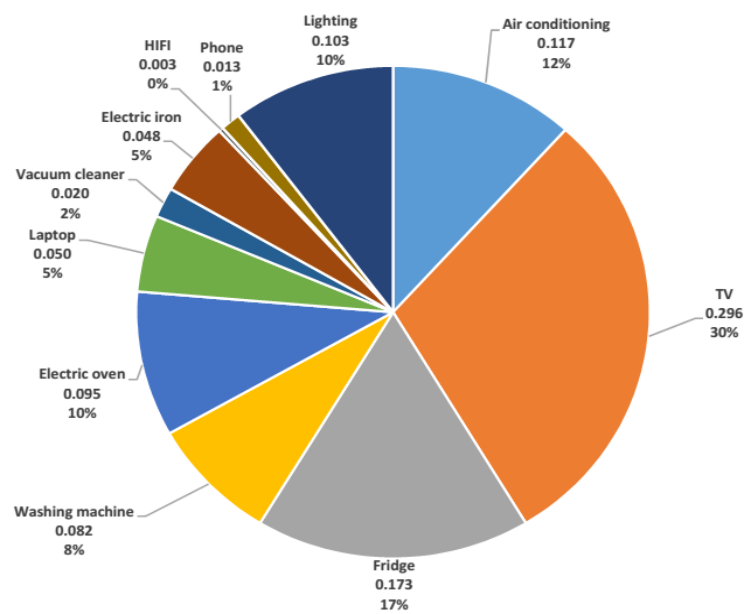

Figure 4. Energy consumption by groups of household appliances

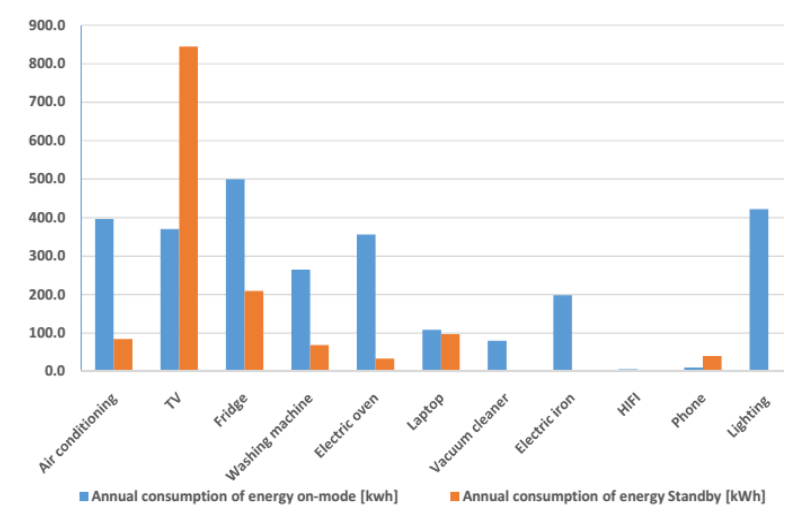


Figure 5. Energy consumption in active and standby modes of household and office equipment

On the data taken in this study, an excess consumption of $34 \%$ (Figure 6) was found to be unreasonably high and a serious discrepancy from the estimated European average consumption in this segment for 2020, amounting to $10 \%$ of total energy consumption per place of residential consumption (according to the IEA [6]). In terms of standby consumption, immediate measures are needed to reduce consumption by identifying solutions to modernise and implement a flexible energy consumption control system for household and office equipment related to residential construction.

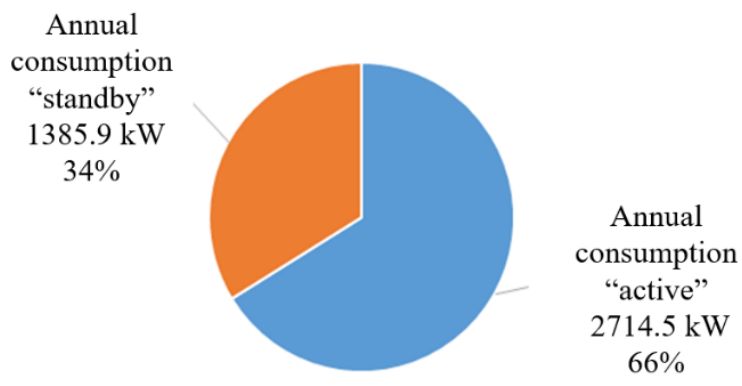

Figure 6. Annual energy consumption in standby and active modes for residential building equipment

Minimizing the loss of energy consumed by the household and office equipment is possible by implementing of a flexible system of control of operating conditions: active (ON), standby (pending) and off-mode (off). The lighting installation is not upgraded because all lamps have only two operating states: on-mode (active) and off-mode. In the off-mode state there are no electricity consumptions. The solution adopted was to add in the electrical installation, directly to the socket (without the lighting installation), appropriate devices for modernising the electrical installations, related to an already inhabited residential construction, without making significant constructive changes to the existing electrical installation. These devices are accessible on the market and with an easy way of installation between the household appliance and the power supply, with parameters in the range 16A, $230 \mathrm{~V}, 3600 \mathrm{~W}$, of several types: adapter sockets with ONOFF switch, ON/OFF adapter sockets with WiFi remote control 433.9MHz, ON/OFF "smart-home" adapter sockets integrated into the $2.4 \mathrm{GHz} \mathrm{WiFi}$ network with smart phone control on Android, programmable switch ON/OFF, ON/OFF switch with twilight light sensor, ON/OFF switch of the "standby killer" type or according to the "Energy Saver" standard. As a principle of operation, these switches are added between the household appliance and the power socket and interrupt the consumer's power supply by remote, manual or automatically and independently (with a twilight sensor or timer). In this way, the standby mode is forced to become off-mode) and standby consumption is significantly reduced or completely eliminated.
The electrical energy assessment carried out on a domestic electrical installation, after modernisation has revealed the following:

- the distribution of the energy consumption by groups of household appliances in the total household consumption has been changed (Figure 7),

- reduced consumption in standby, obviously for smart TVs, (Figure 8),

- annual energy consumption in the active operating mode (including household lighting energy) $E_{\text {mod_activM }}$ of 2760.4 kWh has shown a very small increase.

- annual energy consumption in the standby mode $E_{\text {standbyM }}$ decreased to $589.6 \mathrm{kWh}$, i.e. from $34 \%$ of total energy consumption (initial consumption) to $18 \%$ after modernisation (Figure 9).

- total annual electricity consumption $\mathrm{E}_{\mathrm{i} \_\mathrm{M}}$ decreased to $3350 \mathrm{kWh}$.

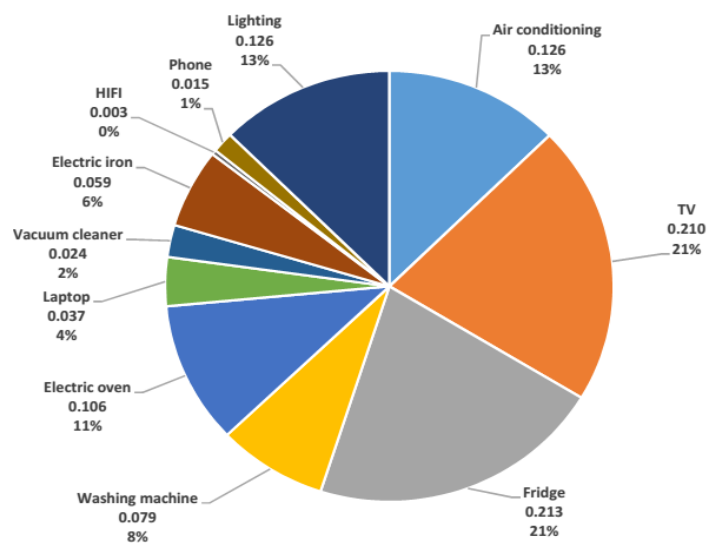

Figure 7. Energy consumption by groups of appliances after modernisation

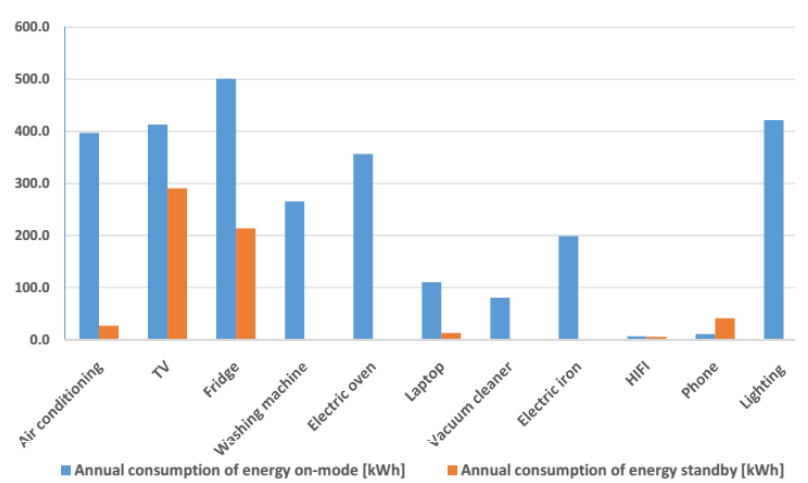

Figure 8. Annual energy consumption, by consumer groups, in the active mode and standby of operation after modernisation

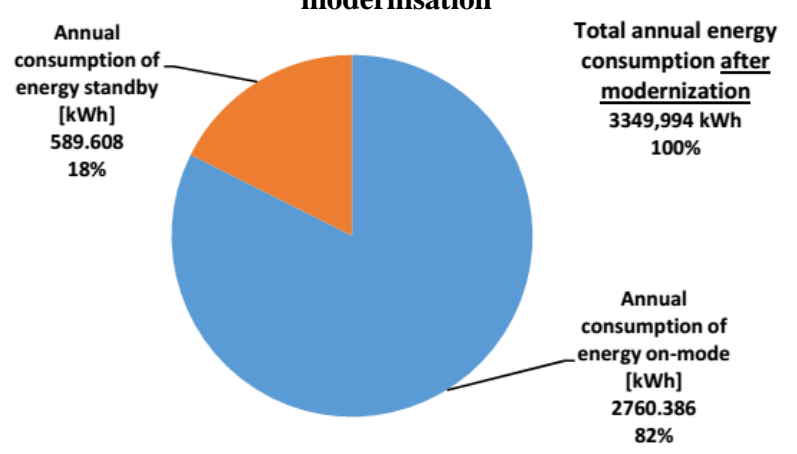


Figure 9. Annual energy consumption in standby mode and active mode relative to all consumption, after modernisation

The energy consumption, when the electrical installation is modernised with controlled ON/OFF switches is shown in Figure 10.

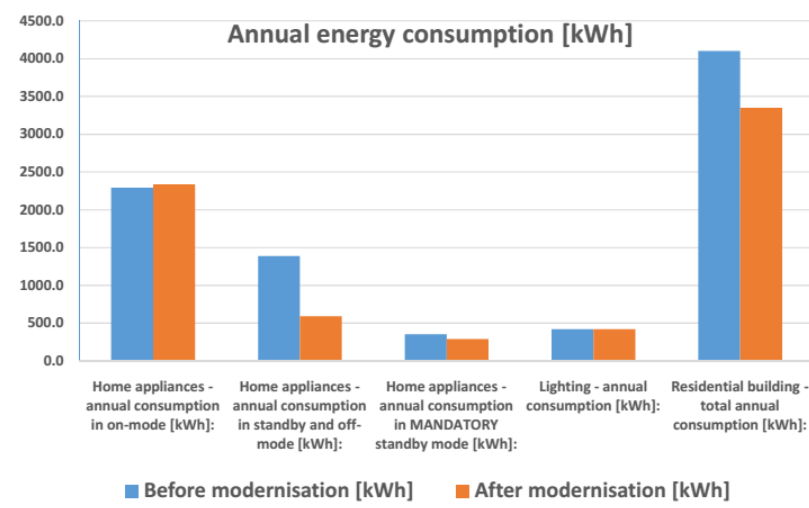

Figure 10. Evolution of energy consumption as a result of the electrical installation modernisation

\section{CONCLUSIONS}

The energy assessment has found that some of the household and office appliances correspond to the energy consumption in the standby operating regime, covered by Regulation (EC), no. 1275/2008, as amended by Regulation (EC), no. 801/2013. For a range of household and office equipment, standby mode is considered necessary, but for a fairly wide range of standby equipment, it is not necessary. In the standby mode of operation some of the electrical and electronic equipment does not perform the functions for which they were created, e.g.: air conditioning, TVs, electric ovens, etc., and the electricity consumed is considered a waste of energy. For other equipment, e.g. smart TVs, the energy consumption in standby mode is unreasonably high.

For the residential building studied, by taking measures to reduce standby consumption, consumption reductions can be made from $35 \%$ to $18 \%$ of the total consumption, i.e. a reductions of $750.4 \mathrm{kWh}$ per year. In addition to the financial effects, this reduction has a environmental beneficial effect, because, according to the estimations of the EU member countries [3], this reduction in the annual energy consumption means a reducing of the $\mathrm{CO} 2$ emissions into the atmosphere by 0.218 tonnes per year (for a dwelling/year at a conversion rate for 2018 of 289.85 $\mathrm{g} \mathrm{CO} 2 / \mathrm{kWh})$.

The standby and off-mode energy consumption of $18 \%$ of the total consumption on residential construction exceeds the EU's 2020 estimate of $10 \%$, but it is still an improvement from the initial situation.

\section{REFERENCES}

[1] Official Journal of the European Union L 339/45, 18.12.2008, Regulation (EC), No. 1275/2008 of 17.12.2008 for implementing Directive 2005/32 / EC of the European Parliament and of the Council.

[2] Official Journal of the European Union L 225/1, 23.08.2013, Regulation (EC) No. 801/2013 of 22.08.2013 amending Regulation (EC) No. $1275 / 2008$.

[3] Energy Efficiency Measures in the Residential Sector, National Energy Regulatory Authority, Department for Energy Efficiency, 2019, [available 15.02.2021 on-line at www.anre.ro].

[4] National Energy Regulatory Authority, Department for Energy Efficiency, Monitoring Report on the implementation of the National Action Plan in the Field of Energy Efficiency (PNAEE), 2015. [available 15.02.2021 on-line at www.anre.ro].

[5] Commission Regulation on proposals to reduce standby electricity consumption, MEMO / 08/488, Brussels, 8 July 2008.

[6] International Energy Agency (IEA), “Cool Appliances, Policy strategies for Energy-Efficient Homes", OECD/IEA 2003, Franța, ISBN: 92-6419661-7 - 2003.

[7] SELINA - Grant agreement No. IEE/07/563/SI2.499206 -,,Standby and Off-Mode Energy Losses In New Appliances Measured in Shops", contractor: ISR - Coimbra University (Portugalia), ISBN: 978-972-8822-21-7, 2010.

[8] DG TREN Impact Assessment. 18/12/2008 Document accompanying the Commission Regulation, implementing Directive 2005/32 / EC on eco-design requirements for the standby and offmode consumption of electrical and electronic equipment for household and office use. Brussels: no., 18/12/2008. SEC (2008) 3071. 